\title{
Editorial
}

\section{The importance of affluence}

Journal of Revenue and Pricing Management (2015) 14, 303-304. doi:10.1057/rpm.2015.33

Rising income has been the driving agent of modern society and is responsible for creating the demanding, sophisticated and wellinformed consumers who drive the purchase of accommodation, holidays and airline tickets. This is cornerstone of Revenue Management. How has the global financial crisis changed that behaviour or has it changed?

Rising income is the key indicator of societal success and responsible for the empowerment of consumers in relation to companies, brands and governments. Increased personal prosperity creates an emboldened consumercitizen, a more demanding, informed actor with intensified expectations of, for instance, quality innovation and premium choices in every market; of efficient and ever-personalised customer service; of visible corporate commitment to tackling the environmental and ethical problems of the day. Following the global economic downturn, one might have anticipated a rebalancing of power within the consumer-company relationship as consumers in many countries witnessed marked declines in both spending power and in the value of key symbols of personal wealth. What we are noticing is that the material and psychological shock of affluence interruption has paradoxically emboldened consumers further. It is a more considered - but no less demanding - approach to consumption that now characterises the behaviour of many as meticulous and waste-conscious, with household budgeting, deal-hunting, product/price comparison and a focus on value for money becoming the norm.

So, can we explain this? With greater wealth, the consumer has demanded better experiences, faster service, multiple choice, social responsibility and greater satisfaction. Against this background, as the world has moved to an experienced economy in which an endless choice through competition and accessibility because of the low cost carrier, and what has emerged is the concept of fluid identity. This trend is about the concept of self that is fluid and malleable in which self cannot be defined by boundaries, within which the choice and the desire for self and new experiences drive consumer consumption. The symbol of this identity is the fact that a consumer on average changes their hairstyle every 18 months (Yeoman, 2008). From a traveller perspective it is about collecting countries, trying new things and the desire for constant change. It means a holiday in Vegas and hedonistic activity at the same time as during a 6-month ecotourism adventure through Africa. However, as wealth decreases that identity becomes simpler, a new thriftiness and desire for simplicity emerge (Yeoman, 2012). This desire for simplicity is driven by inflationary pressures and falling levels of disposable incomes, squeezing the middle class consumer. As the economies of wealth slow down, whatever the reason, new patterns of consumption emerge, whether it is the desire for domestic rather than international travel. A fluid identity means travellers can afford enriching new experiences and indulge themselves at premium five star resorts. They can afford to pay extra for socially conscious consumption, whereas a simple identity means these trends have slowed, halted or reversed. As resources become scarcer, a mindset of a whole generation of travellers change their behaviour. When wealth is great, a fluid identity is the naked scenario however, when a recession emerges, belts are tightened, 
tourists like other consumers search for a simple identity.

While personal affluence will inevitably return (and continue to tower over incomes in developing regions) the memory of affluence interruption (Future Foundation, 2014) will influence consumer behaviour for several years to come, placing companies and brands under intense pressure to re-establish enduring relationships with consumers.

\section{REFERENCES}

Future Foundation (2014) Affluence, https://nvision.futurefoundation.net/, accessed 1 December 2014.

Yeoman, I (2008) Tomorrows Tourist. Amsterdam, The Netherlands: Elsevier.

Yeoman, I (2012) 2050: Tomorrows Tourism. Bristol, UK: Channelview.

Ian Yeoman

Editor

E-mail: ian.yeoman@vuw.ac.nz 